\title{
Distribution of cardiac output and oxygen delivery in an acute animal model of single-ventricle physiology
}

\author{
Marco Ricci, MD, Pierluca Lombardi, MD, Alvaro Galindo, MD, Amelia Vasquez, Jennifer Zuccarelli, \\ and Eliot Rosenkranz, MD
}

From Holtz Children's Hospital, University of Miami Miller School of Medicine, Miami, Fla.

Supported by the Daughtry Family Department of Surgery of the University of Miami.

Received for publication March 25, 2005; revisions received April 11, 2005; accepted for publication May 19, 2005

Address for reprints: Marco Ricci, MD, Division of Cardiothoracic Surgery, University of Miami, Holtz Center 3072 (R-114), 1611 NW 12th Ave, Miami, FL 33136 (Email: mricci@med.miami.edu).

J Thorac Cardiovasc Surg 2005;130:1062-70

$0022-5223 / \$ 30.00$

Copyright $\odot 2005$ by The American Association for Thoracic Surgery

doi:10.1016/j.jtcvs.2005.05.033
Background: When single-ventricle physiology is established acutely (ie, after a Norwood procedure), the combination of limited cardiac output and hypoxemia could result in limited oxygen transport to systemic organs. This study investigates the regional distribution of cardiac output and oxygen delivery after creation of single-ventricle physiology.

Methods: Single-ventricle physiology was created in 8 piglets, and 8 other piglets served as sham control animals. Aortopulmonary shunt, echocardiography-guided atrial septostomy, tricuspid valve avulsion, and pulmonary artery occlusion allowed the left ventricle to support systemic and pulmonary circulations. Physiologic parameters and regional blood flow were determined at baseline and at 30 and 120 minutes after conversion to single-ventricle physiology. Parameters were compared by means of 1-way and 2-way analysis of variance.

Results: Single-ventricle physiology resulted in lower diastolic arterial pressure, oxygen saturation, and arterial oxygen saturation $(P<.05)$, whereas hemoglobin was unchanged. Cerebral blood flow increased markedly in control animals $(P=$ .04). In contrast, in single-ventricle physiology regional blood flow was unchanged in the brain, higher in the myocardium $(P=.1)$, and mildly reduced in low-priority organs (liver, kidneys, and bowel). Cerebral oxygen delivery increased in control animals, whereas in animals with single-ventricle physiology, oxygen delivery decreased in the brain, liver, kidneys, and bowel $(P<.05)$ and was unchanged in the myocardium. Total-body oxygen delivery decreased in animals with singleventricle physiology $(P<.001)$ but not in control animals. Total-body oxygen consumption was unchanged in both groups.

Conclusions: This study shows that in acute single-ventricle physiology hypoxemia and limited regional blood flow reduce oxygen transport to low-priority organs and partly to the brain. These findings might contribute to the understanding of gastrointestinal and neurologic complications in children with single-ventricle physiology.

$\mathrm{N}$ eonates born with single-ventricle physiology (SVP) often require extensive surgical intervention in the neonatal period to accomplish a stable balance between the systemic and the pulmonary circulation (stage I Norwood palliation). Despite the fact that mortality rates for this procedure have decreased in recent years, morbidity in the early postoperative period remains significant for the common occurrence of end-organ dysfunction involving primarily the brain and the gastrointestinal tract. ${ }^{1}$

Recent evidence suggests that in children with complex congenital heart disease, the presence of limited cardiac output $(\mathrm{CO})$ and inadequate regional blood flow might produce significant organ dysfunction. ${ }^{2-4}$ Such risk has been shown to increase in the presence of hypoxemia and reduced arterial oxygen content $\left(\mathrm{CaO}_{2}\right)^{5,6}$ Neonates with SVP are especially vulnerable to inadequate end-organ 

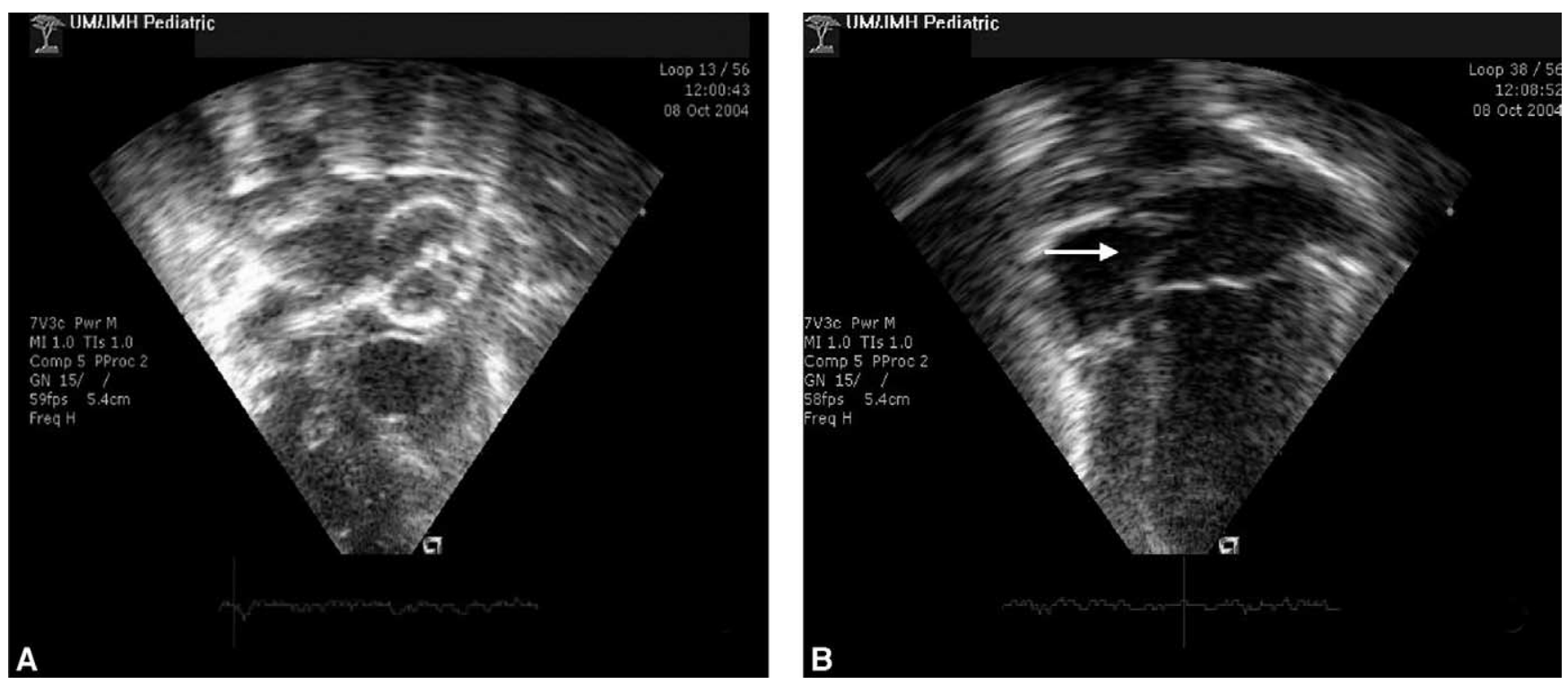

Figure 1. A, Epicardial echocardiography showing the balloon atrial septostomy. B, Single-ventricle physiology model completed. The arrow indicates the atrial septostomy through which the systemic venous return is redirected to the left side of the heart. The picture also demonstrates the adequacy of the tricuspid valve avulsion because the right ventricle is not distended.

oxygen delivery because of the combination of hypoxemia and limited CO reserve. ${ }^{7,8}$

Despite the clinical evidence, these assumptions have not been tested in the laboratory. A few animal models of SVP have been reported in the literature. ${ }^{9-14}$ However, experimental data regarding the consequences of SVP on CO distribution and regional end-organ oxygen transport are lacking. On the basis of these considerations, this study was designed to explore changes in $\mathrm{CO}$ and regional blood flow distribution associated with acute SVP and to establish whether SVP compromises regional oxygen delivery to systemic organs.

\section{Methods}

\section{Animals}

Newborn Yorkshire piglets of $3.7 \pm 0.4 \mathrm{~kg}$ were used. The study was approved by the Animal Care and Use Committee of the University of Miami and carried out in compliance with the 1996 National Research Council guidelines on the Care and Use of Laboratory Animals (National Institutes of Health publication no. 85-23, revised 1985).

\section{Surgical Preparation}

Piglets were anesthetized with intramuscular ketamine $(40 \mathrm{mg} / \mathrm{kg}$ ) and xylazine $(4 \mathrm{mg} / \mathrm{kg})$, intubated through a tracheostomy, and started on volume-control ventilation (tidal volume, $25-30 \mathrm{~mL} / \mathrm{kg}$; rate, 25 breaths/min; inspired oxygen fraction, 0.25; Impact Instrumentation, West Caldwell, NJ). Anesthesia was maintained with fentanyl $\left(50 \mu \mathrm{g} \cdot \mathrm{kg}^{-1} \cdot \mathrm{h}^{-1}\right)$, pancuronium $(0.4$ $\left.\mu \mathrm{g} \cdot \mathrm{kg}^{-1} \cdot \mathrm{h}^{-1}\right)$, and midazolam $\left(0.2 \mathrm{mg} \cdot \mathrm{kg}^{-1} \cdot \mathrm{h}^{-1}\right)$. A catheter was inserted in the femoral artery for pressure monitoring and blood sampling. A 6F introducer sheath was placed in the femoral vein for fluid administration and subsequent insertion of a balloon atrial septostomy catheter. Electrocardiography and rectal temperature were monitored.

The single-ventricle model resembled that described by Randsbaek and colleagues. ${ }^{9,11,12}$ Through a median sternotomy, catheters were placed in the right and left atriums. Heparin was administered $(150 \mathrm{U} / \mathrm{kg}$ ), and a $3.5-\mathrm{mm}$ Gore-Tex shunt (W. L. Gore \& Associates, Inc, Flagstaff, Ariz) was interposed between the aorta (at the takeoff of the innominate artery) and the main pulmonary artery. After the shunt was constructed, a 2-mL balloon septostomy catheter (Medtronic Vascular, Danvers, Mass) was advanced from the right femoral vein into the right atrium. Epicardial 2-dimensional echocardiography was used to direct the catheter across the atrial septum and perform a pull-back septostomy. The same catheter was then advanced into the right ventricle. The tricuspid valve was made incompetent by repeatedly withdrawing the inflated balloon across the valve. Lastly, the shunt was opened, and the main pulmonary artery was occluded. Thus univentricular physiology was created by allowing the left ventricle to support the systemic and pulmonary circulations. The adequacy of the atrial septostomy and tricuspid valve avulsion were confirmed by means of echocardiography and atrial pressure measurements (Figure 1). Of importance, this is a difficult model, and a success rate of approximately $60 \%$ to $70 \%$ can be expected. Most of the failures are related to the difficulty in obtaining an adequate septostomy.

Animals treated as sham control animals received identical preparation. A shunt was constructed with identical surgical ma- 
TABLE 1. Physiologic data

\begin{tabular}{|c|c|c|c|c|}
\hline Variable & Group & Baseline & $30 \mathrm{~min}$ & $120 \mathrm{~min}$ \\
\hline \multirow[t]{2}{*}{ Temperature $\left({ }^{\circ} \mathrm{C}\right)$} & SVP & $36.1 \pm 0.2$ & $35.1 \pm 0.2$ & $36 \pm 0.3$ \\
\hline & Control & $35.4 \pm 0.2$ & $35.8 \pm 0.2$ & $35.8 \pm 0.2$ \\
\hline \multirow[t]{2}{*}{ Heart rate (beats/min) } & SVP & $160 \pm 15$ & $184 \pm 7$ & $195 \pm 5$ \\
\hline & Control & $161 \pm 5$ & $179 \pm 6$ & $171 \pm 2$ \\
\hline \multirow[t]{2}{*}{ Systolic arterial pressure $(\mathrm{mm} \mathrm{Hg})$} & SVP & $113 \pm 4$ & $114 \pm 5$ & $119 \pm 5$ \\
\hline & Control & $112 \pm 8$ & $118 \pm 9$ & $115 \pm 7$ \\
\hline \multirow[t]{2}{*}{ Diastolic arterial pressure $(\mathrm{mm} \mathrm{Hg})$} & SVPt & $67 \pm 4$ & $47 \pm 3^{*}$ & $56 \pm 6$ \\
\hline & Control & $72 \pm 7$ & $75 \pm 7$ & $76 \pm 8$ \\
\hline \multirow[t]{2}{*}{ Mean arterial pressure $(\mathrm{mm} \mathrm{Hg})$} & SVP & $84 \pm 7$ & $69 \pm 7^{*}$ & $79 \pm 8$ \\
\hline & Control & $84 \pm 7$ & $89 \pm 7$ & $85 \pm 8$ \\
\hline \multirow[t]{2}{*}{ Right atrial pressure $(\mathrm{mm} \mathrm{Hg})$} & SVP† & $3.5 \pm 0.5$ & $6.2 \pm 0.8$ & $9.6 \pm 1.7^{*}$ \\
\hline & Control & $2.6 \pm 0.5$ & $2.9 \pm 0.4$ & $3.5 \pm 1.1$ \\
\hline \multirow[t]{2}{*}{ Total LV outflow (mL/min) $\ddagger$} & SVP† & $470 \pm 39$ & $753 \pm 80^{*}$ & $890 \pm 35^{*}$ \\
\hline & Control & $400 \pm 40$ & $396 \pm 38$ & $325 \pm 34$ \\
\hline \multirow[t]{2}{*}{ Systemic CO (mL/min) } & SVP & $470 \pm 39$ & $402 \pm 35$ & $370 \pm 40$ \\
\hline & Control & $400 \pm 40$ & $396 \pm 38$ & $325 \pm 34$ \\
\hline \multirow[t]{2}{*}{ Qp/Qs (ratio) } & SVP & 1 & $0.9 \pm 0.1$ & $1.4 \pm 0.1$ \\
\hline & Control & 1 & 1 & 1 \\
\hline \multirow[t]{2}{*}{ Systemic cardiac index $\left(\mathrm{mL} \cdot \mathrm{kg}^{-1} \cdot \min ^{-1}\right)$} & SVP & $129 \pm 13$ & $109 \pm 45$ & $94 \pm 7$ \\
\hline & Control & $130 \pm 14$ & $123 \pm 14$ & $99 \pm 15$ \\
\hline \multirow[t]{2}{*}{ Arterial pH } & SVP & $7.40 \pm 0.03$ & $7.25 \pm 0.02^{*}$ & $7.28 \pm 0.04$ \\
\hline & Control & $7.39 \pm 0.02$ & $7.30 \pm 0.02$ & $7.33 \pm 0.01$ \\
\hline \multirow[t]{2}{*}{$\mathrm{PCO}_{2}(\mathrm{~mm} \mathrm{Hg})$} & SVP & $38 \pm 3$ & $47 \pm 3$ & $47 \pm 3$ \\
\hline & Control & $33 \pm 3$ & $44 \pm 3$ & $39 \pm 3$ \\
\hline \multirow[t]{2}{*}{ Arterial $\mathrm{O}_{2}$ saturation $(\%)$} & SVPt & $98 \pm 2$ & $67 \pm 2^{*}$ & $74 \pm 2^{*}$ \\
\hline & Control & $99 \pm 1.4$ & $98 \pm 1.5$ & $98 \pm 1.5$ \\
\hline \multirow[t]{2}{*}{ Mixed venous saturation (IVC) (\%) } & SVPt & $73 \pm 2$ & $37 \pm 3^{*}$ & $45 \pm 4^{*}$ \\
\hline & Control & $60 \pm 3$ & $59 \pm 4$ & $59 \pm 5$ \\
\hline \multirow[t]{2}{*}{$\mathrm{Hb}(\mathrm{g} / \mathrm{dL})$} & SVP & $9.3 \pm 0.5$ & $9.4 \pm 0.5$ & $10 \pm 0.6$ \\
\hline & Control & $7.0 \pm 0.5$ & $8.8 \pm 0.5$ & $8.5 \pm 0.5$ \\
\hline \multirow[t]{2}{*}{$\mathrm{CaO}_{2}(\mathrm{~mL} \mathrm{O} / 100 \mathrm{~mL})$} & SVPt & $12.8 \pm 0.7$ & $8.5 \pm 0.7$ & $11 \pm 0.8$ \\
\hline & Control & $10 \pm 0.7$ & $12 \pm 0.7$ & $11.8 \pm 0.7$ \\
\hline \multirow[t]{2}{*}{ Body $\mathrm{O}_{2}$ delivery, indexed $\left(\mathrm{mL} \mathrm{O}_{2} \cdot \mathrm{kg}^{-1} \cdot \min ^{-1}\right)$} & SVPt & $15.9 \pm 1$ & $9.2 \pm 1.5^{*}$ & $10 \pm 1.8$ \\
\hline & Control & $12.6 \pm 1.3$ & $15.5 \pm 1.5$ & $11.9 \pm 2$ \\
\hline \multirow[t]{2}{*}{ Arterial lactate $(\mathrm{mmol} / \mathrm{L})$} & SVP & $2.8 \pm 1.5$ & $11 \pm 1.5^{*}$ & $8.9 \pm 1.7^{*}$ \\
\hline & Control & $3.8 \pm 1.5$ & $6.5 \pm 1.5$ & $6.2 \pm 1.6$ \\
\hline
\end{tabular}

Values are expressed as means \pm standard error of the mean. SVP, Single-ventricle physiology; $L V$, Left ventricular; $C O$, cardiac output; IVC, inferior vena cava; $\mathrm{Hb}$, hemoglobin; $\mathrm{CaO}_{2}$, arterial oxygen content. $* P<.05$ within group (1-way analysis of variance). $\uparrow P<.05$ intergroup (2-way analysis of variance). ‡Left ventricular outflow, excluding coronary flow.

neuvers and clamped. The atrial septostomy and tricuspid valve avulsion were simulated by manipulating the catheter against or across the atrial septum and tricuspid valve without inflating the balloon. These piglets were kept in a biventricular state.

\section{Experimental Protocol}

Eight piglets were included in the study group (SVP group), and 8 were treated as sham-operated control animals. Both groups were ventilated at a constant fraction of inspired oxygen of $25 \%$, whereas the $\mathrm{PCO}_{2}$ was maintained at 35 to $45 \mathrm{~mm} \mathrm{Hg}$. Rectal temperature was kept at $35.5^{\circ} \mathrm{C}$ to $36.5^{\circ} \mathrm{C}$. On the basis of experience from pilot experiments, a standard regimen was developed to facilitate establishing our SVP model. Throughout the experiments, normal saline $\left(4 \mathrm{~mL} \cdot \mathrm{kg}^{-1} \cdot \mathrm{h}^{-1}\right)$, dopamine $(5-10$ $\left.\mu \mathrm{g} \cdot \mathrm{kg}^{-1} \cdot \min ^{-1}\right)$, and epinephrine $\left(0.05-0.1 \mu \mathrm{g} \cdot \mathrm{kg}^{-1} \cdot \mathrm{min}^{-1}\right)$ were administered to maintain cardiovascular stability and to avoid hemodynamic perturbations. Inotropic support was begun in both groups as soon as intravascular lines were inserted. Small adjustments were made so as to maintain the systolic blood pressure as close as possible to baseline measurements. Fresh whole blood obtained from an adult pig was infused to replace blood losses and maintain hemoglobin concentrations as close to baseline as possible $(55 \pm 25 \mathrm{~mL})$. An identical protocol was used in the control group.

Physiologic measurements were obtained at baseline and at 30 and 120 minutes after conversion to SVP. These included hemodynamic parameters, blood sampling (arterial and central venous) for gas analysis and determination of hemoglobin and lactate 


\section{SVP}

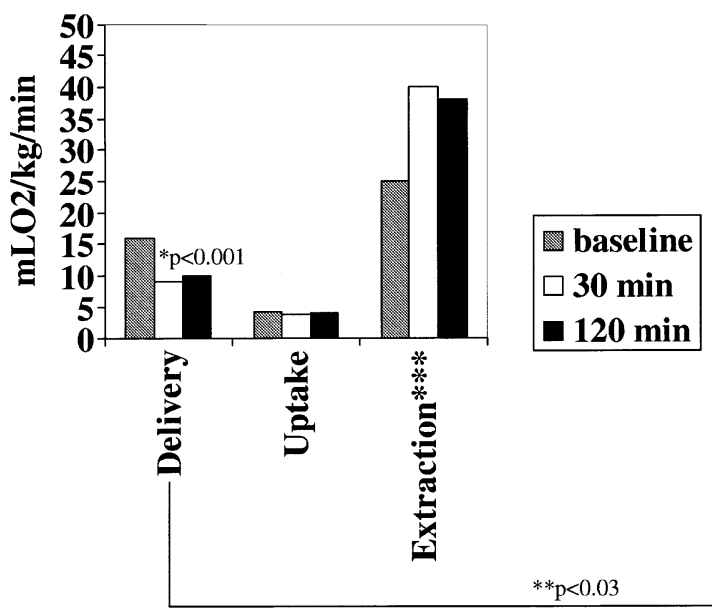

\section{Controls}

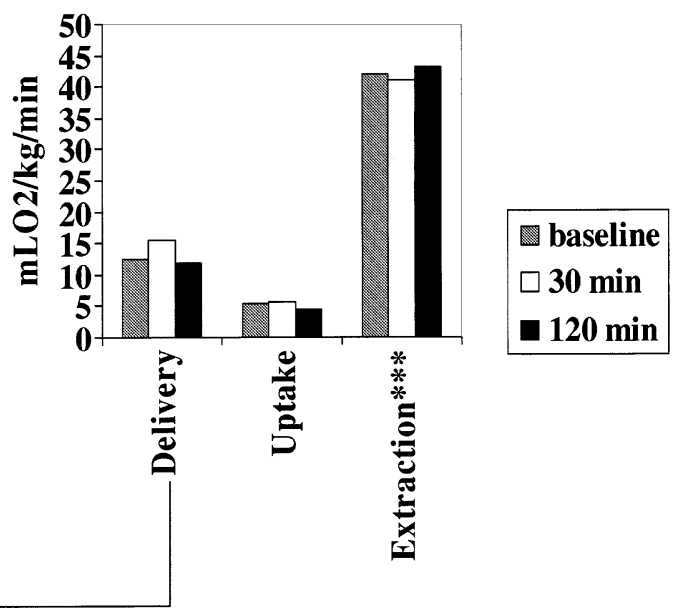

Figure 2. Changes in total-body oxygen delivery indexed (in milliliters of oxygen per kilogram per minute), uptake (in milliliters of oxygen per kilogram per minute), and fractional oxygen extraction (in percentages) at baseline and at subsequent experimental points. Flow calculations were made with an electromagnetic flowmeter. In singleventricle physiology $(S V P)$ there was a significant decrease in total-body oxygen delivery $(P<.01$ within group, and $\boldsymbol{P}=.03$ intergroup). 0xygen uptake was unchanged in both groups. ${ }^{*} \boldsymbol{P}<.05,1$-way analysis of variance. ${ }^{* *} P<.05,2-$ way analysis of variance. ${ }^{* *}$ Fractional oxygen extraction expressed as a percentage.

levels, determination of total CO (excluding coronary flow) with a perivascular electromagnetic flowmeter, and determination of regional blood flow by means of stable-isotope microsphere injections. Blood sampling to measure the central venous saturation in SVP was carried out from a venous line positioned in the high inferior vena cava so as to avoid contamination with the left atrial blood after the atrial septostomy. This was done because of the technical difficulties in advancing and maintaining the catheter in the superior vena cava. At completion, an autopsy was performed to confirm the correct positioning of all indwelling catheters, the adequacy of the atrial septostomy, and the adequacy of the shunt anastomoses. The brain, heart, liver, small bowel, and kidneys were removed and weighed. Multiple tissue samples from each organ were obtained for regional blood flow determinations. Values obtained from different samples of the same organ were averaged for blood flow calculations.

In control animals measurements were obtained at baseline and at 30 and 120 minutes after the simulated septostomy.

\section{Regional Blood Flow Determinations}

Stable-isotope microspheres $(15 \pm 5 \mu \mathrm{m}$; BioPhysics Assay Laboratory, Inc, Worcester, Mass) were used, as described by others. ${ }^{15}$ Microspheres labeled with nonradioactive isotopes (gold, samarium, ytterbium, and lutetium) were administered over 3 seconds through the left atrial catheter, and reference samples were collected over 90 seconds from the femoral artery $(2 \mathrm{~mL} / \mathrm{min})$. A total of $1 \times 10^{6}$ microspheres were injected in the biventricular state, whereas $2.5 \times 10^{6}$ were injected in SVP. Experience with microspheres in SVP is lacking in the literature. On the basis of previous pilot experiments, we demonstrated that $2.5 \times 10^{6} \mathrm{mi}-$ crospheres in the univentricular state compensated for runoff through the pulmonary circulation and ensured adequate microsphere concentration in systemic organs. At the end of the experiment, tissue samples were weighed fresh and dried in a warming oven at $60^{\circ} \mathrm{C}$ for 48 hours. Dried samples were sent for analysis to BioPhysics Assay Laboratory and processed by means of neutron activation. ${ }^{15}$ This technique entails exposure of the isotope to a neutron beam and activation into a radioactive nucleus. Activated labels are then allowed to decay for 48 hours, during which time gamma rays are emitted and measured. The signal is proportional to the label concentration in the sample. ${ }^{15}$ Results of the assay for each label are reported in disintegrations per minute (dpm). Regional blood flow is expressed in milliliters per minute per $100 \mathrm{~g}$ and calculated by normalizing the concentration of microspheres in the tissue sample (dpm per gram) to the concentration in the reference sample $(\mathrm{dpm} \times$ minute $\times$ milliliters). The fresh tissue weight was used for all regional blood flow calculations.

\section{Physiologic Measurements and Calculations}

Total CO (excluding coronary blood flow) was determined by using an electromagnetic flowmeter (Transonic Systems, Ithaca, NY) placed on the ascending aorta. After conversion to SVP, pulmonary blood flow was determined by placing the flowmeter on the pulmonary artery distal to the aortopulmonary shunt, as described by others..$^{9,11-13}$ In SVP total systemic blood flow was calculated as follows:

Total cardiac output ( $\mathrm{mL} / \mathrm{min}$ )-Pulmonary blood flow ( $\mathrm{mL} / \mathrm{min}$ ).

Calculations of oxygen metabolism were performed by using the following equations:

1. $\mathrm{CaO}_{2}=\left(\mathrm{Hb} \times 1.36 \times \mathrm{SaO}_{2}\right)+\left(0.0031 \times \mathrm{PaO}_{2}\right)$ 
TABLE 2. Changes in regional blood flow and oxygen delivery to systemic organs, as determined by microsphere injection

\begin{tabular}{|c|c|c|c|c|c|c|}
\hline & Group & Baseline & $30 \mathrm{~min}$ & $120 \mathrm{~min}$ & 1-way ANOVA & 2-way ANOVA \\
\hline \multicolumn{7}{|l|}{ Regional blood flow (mL $\left.\cdot \min ^{-1} \cdot 100 \mathrm{~g}\right)$} \\
\hline \multirow[t]{2}{*}{ Brain } & SVP & $63 \pm 8$ & $77 \pm 8$ & $61 \pm 9$ & NS & NS \\
\hline & Control & $64 \pm 6$ & $98 \pm 12$ & $94 \pm 9$ & $P=.04$ & \\
\hline \multirow[t]{2}{*}{ Heart } & SVP & $247 \pm 50$ & $459 \pm 54$ & $311 \pm 62$ & $P=.1$ & NS \\
\hline & Control & $233 \pm 54$ & $217 \pm 50$ & $193 \pm 53$ & NS & \\
\hline \multirow[t]{2}{*}{ Liver } & SVP & $14.4 \pm 3$ & $11.7 \pm 3$ & $8.8 \pm 3$ & NS & NS \\
\hline & Control & $15 \pm 4$ & $12.7 \pm 3$ & $11 \pm 3$ & NS & \\
\hline \multirow[t]{2}{*}{ Small bowel } & SVP & $58 \pm 9$ & $54 \pm 10$ & $23 \pm 11$ & $P=.09$ & NS \\
\hline & Control & $56 \pm 8$ & $42 \pm 9$ & $34 \pm 9$ & NS & \\
\hline \multirow[t]{2}{*}{ Kidneys } & SVP & $97 \pm 19$ & $58 \pm 19$ & $58 \pm 22$ & $P=.1$ & NS \\
\hline & Control & $98 \pm 19$ & $104 \pm 20$ & $80 \pm 20$ & NS & \\
\hline \multicolumn{7}{|l|}{ Regional $\mathrm{O}_{2}$ delivery $\left(\mathrm{mL} \mathrm{O}_{2} \cdot \min ^{-1} \cdot 100 \mathrm{~g}\right)$} \\
\hline \multirow[t]{2}{*}{ Brain } & SVP & $8.5 \pm 1.1$ & $6.4 \pm 1$ & $6.3 \pm 1.5$ & NS & $P=.05$ \\
\hline & Control & $6.4 \pm 1.1$ & $12.3 \pm 2$ & $11.6 \pm 2$ & $P=.05$ & \\
\hline \multirow[t]{2}{*}{ Heart } & SVP & $30 \pm 5$ & $41 \pm 6$ & $33 \pm 6$ & NS & NS \\
\hline & Control & $20 \pm 5$ & $25 \pm 5$ & $19 \pm 4$ & NS & \\
\hline \multirow[t]{2}{*}{ Liver } & SVP & $1.7 \pm 0.3$ & $0.9 \pm 0.3$ & $0.8 \pm 0.4$ & $P=.02$ & NS \\
\hline & Control & $1.5 \pm 0.2$ & $1.5 \pm 0.3$ & $1.3 \pm 0.3$ & NS & \\
\hline \multirow[t]{2}{*}{ Small bowel } & SVP & $7.3 \pm 1.1$ & $4.4 \pm 1$ & $2.3 \pm 0.8$ & $P=.03$ & NS \\
\hline & Control & $5.3 \pm 1$ & $5 \pm 1$ & $4 \pm 0.8$ & NS & \\
\hline \multirow[t]{2}{*}{ Kidneys } & SVP & $13.2 \pm 2.5$ & $4.9 \pm 2.3$ & $4.3 \pm 2.7$ & $P=.01$ & $P=.07$ \\
\hline & Control & $11.1 \pm 2$ & $14 \pm 2.8$ & $10.4 \pm 2.5$ & NS & \\
\hline
\end{tabular}

$P$ values of less than .1 are shown. ANOVA, analysis of variance; SVP, single-ventricle physiology; $N S$, not significant.

2. Total Body $\mathrm{O}_{2}$ Delivery, Indexed $\left(\mathrm{mLO}_{2} \cdot \mathrm{kg}^{-1} \cdot \mathrm{min}^{-1}\right.$; by Flowmeter $)=($ Blood flow $\div$ Weight $) \times \mathrm{CaO}_{2}$

3. Total Body $\mathrm{O}_{2}$ Uptake, Indexed $\left(\mathrm{mLO}_{2} / \mathrm{kg}^{-1} / \mathrm{min}^{-1}\right.$; by Flowmeter $)=\left(\right.$ Arterial $\mathrm{O}_{2}$ content $-\mathrm{IVCO}_{2}$ content $)$ $\times$ Blood Flow

4. Total Body Fractional $\mathrm{O}_{2}$ Extraction Ratio (\%) $=\left(\right.$ Total Body $\mathrm{O}_{2}$ Uptake $) \div\left(\right.$ Total Body $\mathrm{O}_{2}$ Delivery $)$ $\times 100$

5. Regional $\mathrm{O}_{2}$ Delivery $\left(\mathrm{mLO} \mathrm{O}_{2} \mathrm{~min}^{-1} / 100 g\right.$; by Microspheres $)=($ Regional Blood Flow $) \times \mathrm{CaO}_{2}$

\section{Statistical Analysis}

All data are expressed as means \pm standard error of the mean. Comparisons within each group and between groups were made by using 1-way and 2-way analysis of variance. Tukey post hoc testing was used to detect statistically significant differences among the study periods and between groups at specific data points. A commercially available software package was used (SigmaStat 2.0 for Windows; SPSS Inc, Chicago, Ill).

\section{Results}

Physiologic parameters are summarized in Table 1. Temperature, hemoglobin, and $\mathrm{PCO}_{2}$ were comparable in both groups. Creation of SVP resulted in lower mean arterial pressure, arterial oxygen saturation, arterial $\mathrm{pH}$, and $\mathrm{CaO}_{2}(P$ $<.05$ ), whereas total left ventricular output increased by nearly $100 \%(P<.05)$. Dopamine administration did not differ between the SVP and control groups (from $7.1 \pm 0.8$ to $7.8 \pm 0.8$ to $6.5 \pm 0.8 \mu \mathrm{g} \cdot \mathrm{kg}^{-1} \cdot \mathrm{min}^{-1}$ in SVP animals at baseline, 30 minutes, and 120 minutes, respectively, versus $8.5 \pm 0.7$ to $8.5 \pm 0.7$ to $8.5 \pm 0.7 \mu \mathrm{g} \cdot \mathrm{kg}^{-1} \cdot \mathrm{min}^{-1}$ in control animals; $P=.7$ ), nor did epinephrine administration (from $0.07 \pm 0.01$ to $0.07 \pm 0.01$ to $0.06 \pm 0.01$ $\mu \mathrm{g} \cdot \mathrm{kg}^{-1} \cdot \min ^{-1}$ in SVP animals at baseline, 30 minutes, and 120 minutes, respectively, versus $0.06 \pm 0.008$ to 0.06 \pm 0.008 to $0.060 .008 \mu \mathrm{g} \cdot \mathrm{kg}^{-1} \cdot \mathrm{min}^{-1}$ in control animals; $P=.9$ ).

Figure 2 shows changes in total-body oxygen delivery, oxygen uptake, and fractional oxygen extraction. There was a significant decrease in total-body oxygen delivery indexed by body weight (in milliliters of oxygen per kilogram per minute) in the SVP group $(P<.001)$, whereas this was unchanged in control animals throughout the experiment. The indexed total-body oxygen uptake was unchanged in both groups. Fractional oxygen extraction trended higher in SVP animals, whereas it was unaffected in control animals.

Changes in regional blood flow to systemic organs are shown in Table 2. Cerebral blood flow (CBF) increased by approximately $50 \%$ at 30 and 120 minutes in control animals $(P=.04)$. Conversely, it remained unchanged in the SVP group, despite these animals having a lower $\mathrm{CaO}_{2}$. In the SVP group there was a trend toward higher regional blood flow to the myocardium $(P=.1)$ and lower regional blood flow to the liver, small bowel $(P=.09)$, and kidneys $(P=.1)$. Variations in regional blood flow as percentage 


\section{SVP}

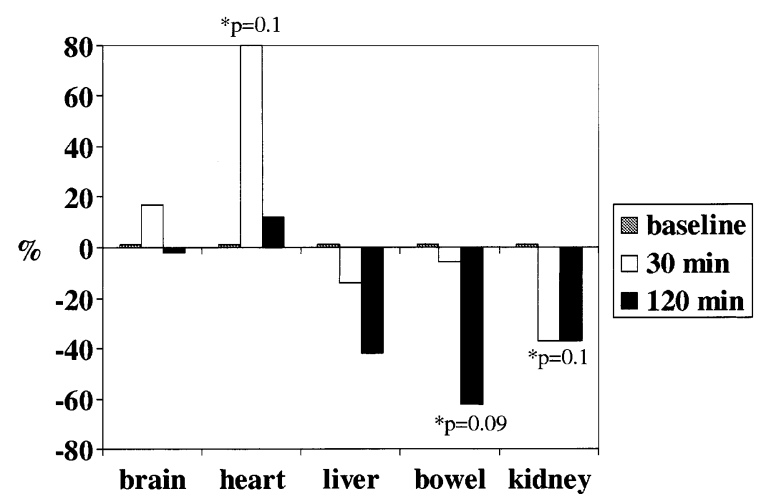

Controls

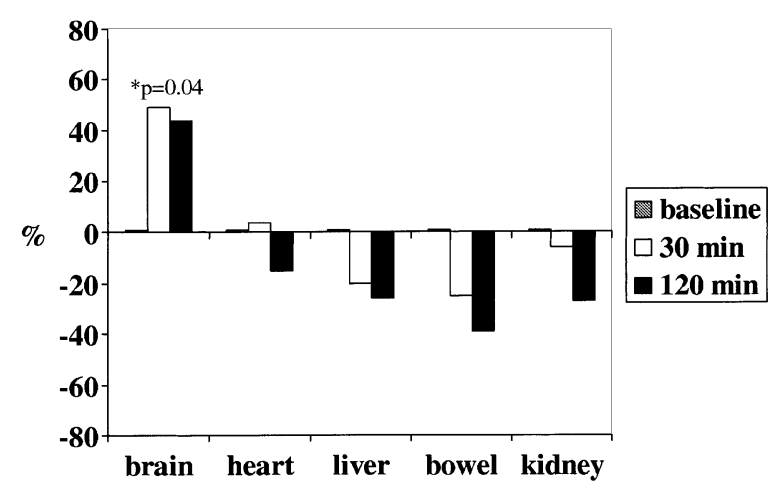

Figure 3. Regional blood flow expressed as percentage change from baseline during the experimental time points. In control animals regional blood flow decreased slightly in low-priority organs, whereas it increased sharply in the brain $(P=.04)$. In the single-ventricle physiology $(S V P)$ group the redistribution after creation of singleventricle physiology was more notable; regional blood flow decreased in low-priority organs $(P=.09-1)$, was unchanged in the brain, and increased in the heart $(P=.1)$. None of the intergroup differences were statistically significant. ${ }^{*} P<.1,1$-way analysis of variance.

change from baseline in SVP and control group animals are also shown in Figure 3.

Changes in oxygen delivery to the end organs studied are shown in Table 2. In SVP there was a significant decrease in oxygen delivery to the brain $(P=.05)$, liver, small bowel, and kidneys $(P<.05)$, whereas oxygen delivery was unchanged in the myocardium. Conversely, oxygen delivery to all regions was unchanged in control animals, except in the brain, where a significant increase was noted $(P=.05)$. Variations in oxygen delivery as percentage change from baseline are also shown in Figure 4.

\section{Discussion}

The most relevant finding of this investigation is that SVP created acutely in piglets resulted in profound changes in $\mathrm{CO}$ distribution to systemic organs such that blood flow was initially redistributed away from low-priority organs (liver, kidneys, and small bowel) to high-priority organs (heart and brain). However, although the increase in myocardial blood flow was sufficient to offset the effect of the decreasing $\mathrm{CaO}_{2}$ and therefore preserve myocardial oxygen delivery, the increase in $\mathrm{CBF}$ was negligible and inadequate to maintain cerebral oxygen delivery. Under our experimental conditions, the significant decrease in regional blood flow to low-priority organs and the diminished $\mathrm{CaO}_{2}$ resulting from the creation of SVP were responsible for the profound decreases in oxygen delivery to these territories.

Experimental studies have shown that in animals with biventricular circulation in which acute hypoxia is introduced in isolation, $\mathrm{CO}$ increases substantially in an attempt at maintaining adequate oxygen delivery to the periphery. ${ }^{16}$ However, regional blood flow increases selectively, in certain areas (brain and myocardium) more than in others (gastrointestinal). ${ }^{17,18}$ With severe hypoxia, CBF has been shown to increase so profoundly that cerebral oxygen delivery is maintained within normal baseline levels. ${ }^{16-18}$ This phenomenon has been observed also in situations in which acute hypoxia is combined with a reduction in $\mathrm{CO} .^{19,20}$

Our study also entailed the acute introduction of hypoxemia and the simultaneous reduction in systemic flow as part of the acute creation of SVP. However, we observed that the increase in CBF was insufficient to maintain cerebral oxygen delivery. In fact, in our SVP model cerebral oxygen delivery decreased by $25 \%$ at 30 minutes and remained low at 120 minutes, whereas it increased by $70 \%$ in control animals $(P=.05)$. The mechanisms leading to such an increase in CBF and cerebral oxygen delivery in control animals are uncertain. The inotropic management was similar in both groups, as previously noted. It could be hypothesized that this phenomenon was due to the surgical maneuvers and to the partial clamping of the aorta at the origin of the innominate artery, which was required to insert the aortopulmonary shunt. This might have produced a transient decrease in cerebral perfusion, followed by a vasodilatory response in the cerebral circulation once the clamp was released. Of note, these maneuvers were performed in an identical fashion in both study groups. The increase in CBF at 30 minutes observed in control animals could therefore be interpreted as a hyperemic response to a transient period of precarious CBF. In contrast, in SVP there was no compa- 


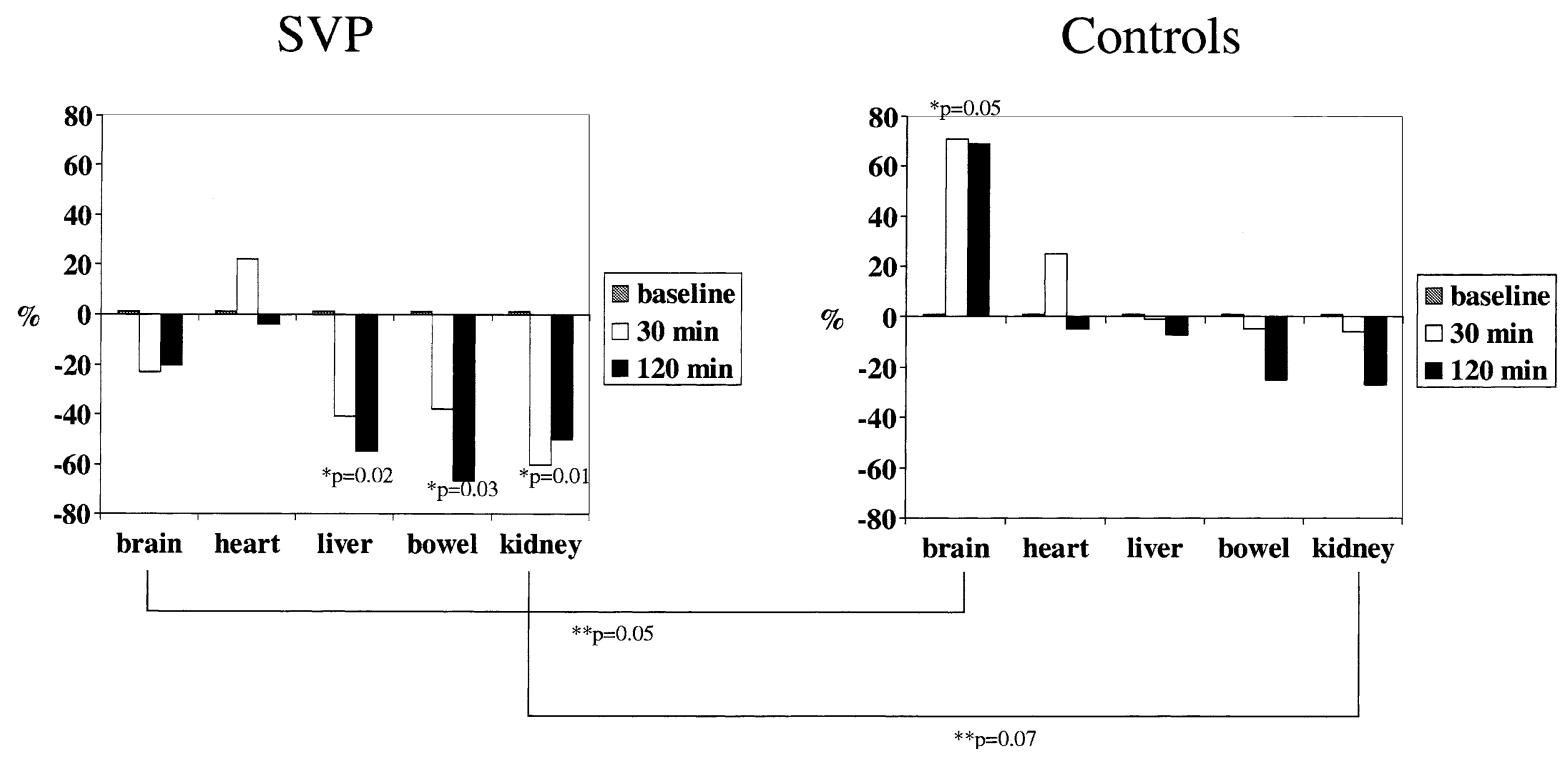

Figure 4. Regional oxygen delivery expressed as percentage change from baseline during the experimental time points. In control animals regional oxygen delivery increased significantly in the brain $(P=.05)$ and was unchanged in the heart, whereas modest decreases were seen in low-priority organs. In the single-ventricle physiology (SVP) group profound decreases were seen in the liver $(P=.02)$, small bowel $(P=.03)$, and kidneys $(P=.01)$ after creation of single-ventricle physiology; also, oxygen delivery decreased modestly in the brain and was unchanged in the myocardium. Oxygen delivery to the brain and to the kidneys was lower in the singleventricle physiology group than in the control group $\left(P=.05\right.$ and $P=.07$, respectively). ${ }^{*} P<.1,1$-way analysis of variance. ${ }^{* *} P<.1,2$-way analysis of variance.

rable hyperemic response because the increase in CBF was significantly blunted. In contrast to brain blood flow, myocardial blood flow increased sufficiently in our SVP piglets to preserve myocardial oxygen delivery, suggesting that in acute SVP the myocardium retains the ability to increase regional blood flow and attract a greater proportion of $\mathrm{CO}$, even in the face of diastolic runoff through the aortopulmonary shunt. Also, we cannot exclude that the increase in CBF noted in control animals might have been partly related to a stress response. The anesthetic management in our study was similar to that used in other studies with the same species. Most importantly, an identical anesthetic protocol was used in the SVP and control groups. It is possible that the stress response contributed to the notable increase in CBF in control animals, whereas SVP animals were unable to produce the same $\mathrm{CBF}$ increase, although they were able to increase myocardial blood flow. Regarding differences in CBF between the right and left hemispheres, on the basis of the microsphere data, we were unable to determine whether there was a difference caused by diastolic runoff through the shunt. In previous SVP pilot experiments (unpublished data) in which we measured carotid flow with an electromagnetic flowmeter, we found no difference between the left and right hemispheres. Regarding changes in regional blood flow and oxygen delivery to low-priority organs, our findings in SVP piglets are consistent with those of others $^{19-21}$ in which various combinations of hypoxia and $\mathrm{CO}$ reduction were used. Interestingly, a trend toward lower regional blood flow to the liver, kidneys, and small bowel was also observed in the control group, indicating that the overall effect of our experimental conditions on the animals was severe enough to cause a stress response and, consequently, some degree of CO redistribution. In SVP piglets, however, the decrease in regional blood flow to low-priority organs was far more profound. This phenomenon, combined with the lower $\mathrm{CaO}_{2}$ value observed with conversion to SVP, resulted in significant decreases in oxygen delivery to the liver $(-55 \%)$, kidneys $(-50 \%)$, and small bowel $(-67 \%)$. These changes were notable at 30 minutes after conversion from the biventricular to univentricular state and persisted at 120 minutes, which would exclude the possibility of a transient phenomenon. In our experiment we did not measure oxygen content in the portal vein, and therefore we were unable to draw conclusions on the adequacy of oxygen delivery in sustaining intestinal metabolic demands. The possibility that severe regional hypoxia might have occurred in our SVP model is confirmed by the profound lactate acidosis noted in these animals, whereas a more moderate increase in systemic lactate and mild acidosis was also noted in the control group. Despite the increase in central venous pres- 
sure from $3.5 \pm 0.5$ to $9.6 \pm 1.7 \mathrm{~mm} \mathrm{Hg}$ between baseline and 120 minutes being statistically significant (Table 1), we believe that this factor alone is insufficient to explain the decrease in systemic organ perfusion. In our SVP animals, the indexed whole-body oxygen delivery decreased by $50 \%$ after conversion to SVP at 30 minutes and remained decreased at 120 minutes. The fact that in SVP total-body oxygen uptake was unchanged concomitantly with the significant decrease in oxygen delivery and the significant increase in circulating lactate suggests that regional tissue hypoxia might have occurred in some territories.

Our findings must be interpreted in light of several important limitations inherent with the experimental model. Whether the experimental conditions reproduced in our model mirror clinical SVP is unknown. Our piglets were born with normal cardiac physiology, and SVP was created acutely by having the left ventricle as the sole functional ventricle, unlike clinical situations, such as hypoplastic left heart syndrome.

To establish our SVP model, we avoided the use of cardiopulmonary bypass, hypothermia, and circulatory arrest to eliminate the effects of additional confounding variables, ${ }^{22,23}$ although this might not completely replicate what occurs in the clinical setting. Additional limitations relate to the short period of observation, dictated by the limited period of hemodynamic stability of the SVP model, and by the relatively low level of hemoglobin that our piglets were found to have at baseline. In our experiments we maintained the hematocrit level as close to baseline as possible by transfusing fresh blood as the experiment proceeded. This was to preserve baseline physiologic conditions and restrict the focus on the effects of SVP. Had we transfused all animals to reach a higher level of hemoglobin similar to that believed to be desirable in human SVP, the decrease in oxygen delivery noted in some organs might have been less severe. This is an important question that requires further investigation. Additional limitations relate to the fact that we did not measure intracranial pressure, and therefore we could not estimate cerebral vascular resistance. Also, the significant increase in central venous pressure noted in the SVP group as opposed to the control group could have influenced negatively regional blood flow to low-priority organs. An additional weakness of the model is that we measured mixed venous saturation from the inferior vena cava because of the technical difficulty of superior vena caval cannulation. This might have introduced an important bias when estimating total-body oxygen consumption.

Despite these limitations, this study helps to demonstrate the cardiovascular changes occurring in various vascular beds in acute SVP and provides a new insight into the cause of end-organ dysfunction in children with SVP. Our findings suggest that in acute SVP the redistribution of $\mathrm{CO}$ favors the myocardium over the brain and that low-priority organs, such as the liver, kidneys, and intestine, are severely penalized, which might put them at risk for further injury during episodes of hemodynamic instability, as often occurs in the postoperative course of children undergoing stage 1 Norwood palliation. Furthermore, our study also suggests that the hypoxemia and the concomitant redistribution of systemic blood flow associated with acute SVP can adversely affect oxygen transport to low-priority organs and to the brain, although this might not hold true should the oxygen carrying capacity be simultaneously increased.

We thank Dr Erle H. Austin and Dr Kenneth G. Proctor for their guidance.

\section{References}

1. Gaynor JW, Mahle WT, Cohen MI, Ittenbach RF, DeCampli WM, Steven JM, et al. Risk factors for mortality after the Norwood procedure. Eur J Cardiothorac Surg. 2002;22:82-9.

2. Ferriero DM. Neonatal brain injury. N Engl J Med. 2004;351:1985-95.

3. Sie LT, Van der Knaap MS, Oosting J, de Vries LS, Lafeber HN, Valk J. MR patterns of hypoxic-ischemic brain damage after prenatal, perinatal, and postnatal asphyxia. Neuropediatrics. 2000;31:128-36.

4. Licht DJ, Wang J, Silvestre DW, Nicolson SC, Montenegro LM, Wernovsky G, et al. Preoperative cerebral blood flow is diminished in neonates with severe congenital heart defects. J Thorac Cardiovasc Surg. 2004;128:841-9.

5. Mahle WT, Tavani F, Zimmerman RA, Nicolson SC, Galli KK, Gaynor JW, et al. An MRI study of neurological injury before and after congenital heart surgery. Circulation. 2002;106(suppl I):I109-14.

6. Limperopoulos C, Majnemer A, Shevell MI, Rohlicek C, Rosenblatt B, Tchervenkov C, et al. Predictors of developmental disabilities after open heart surgery in young children with congenital heart defects. J Pediatr. 2002;141:51-8.

7. Hoffman GM, Ghanayem NS, Kampine JM, Berger S, Mussatto KA, Litwin SB, et al. Venous saturation and the anaerobic threshold in neonates after the Norwood procedure for hypoplastic left heart syndrome. Ann Thorac Surg. 2000;70:1515-20.

8. Glauser TA, Rorke LB, Weinberg PM, Clancy RR. Congenital brain anomalies associated with the hypoplastic left heart syndrome. Pediatrics. 1990;85:984-90.

9. Randsbaeck F, Riordan CJ, Storey JH, Montgomery WD, Santamore WP, Austin EH. Animal model of the univentricular heart and single ventricular physiology. J Invest Surg. 1996;9:375-84.

10. Reddy VM, Liddicoat JR, McElhinney DB, Fineman JR, Klein JR, Chang R, et al. Hemodynamic effects of epinephrine, bicarbonate, and calcium in the early postnatal period in a lamb model of singleventricle physiology created in utero. J Am Coll Cardiol. 1996;28: 1877-83.

11. Riordan CJ, Randsbaek F, Storey JH, Montgomery WD, Santamore WP, Austin EH. Effects of oxygen, positive end-expiratory pressure, and carbon dioxide on oxygen delivery in an animal model of the univentricular heart. J Thorac Cardiovasc Surg. 1996;112:644-54.

12. Riordan CJ, Randsbaek F, Storey JH, Montgomery WD, Santamore WP, Austin EH. Inotropes in the hypoplastic left heart syndrome: effects in an animal model. Ann Thorac Surg. 1996;62:83-90.

13. Mora GA, Pizarro C, Jacobs ML, Norwood WI. Experimental model of single ventricle. Influence of carbon dioxide on pulmonary vascular dynamics. Circulation. 1994;90(suppl II):II43-6.

14. Kitaichi T, Chikugo F, Kawahito T, Hori T, Masuda Y, Kitagawa T. Suitable shunt size for regulation of pulmonary blood flow in a canine model of univentricular parallel circulations. $J$ Thorac Cardiovasc Surg. 2003;125:71-8.

15. Reinhardt CP, Dalhberg S, Tries MA, Marcel R, Leppo JA. Stable labeled microspheres to measure perfusion: validation of a neutron 
activation assay technique. Am J Physiol Heart Circ Physiol. 2001;280:H108-16.

16. Davidson D, Stalcup SA, Mellins RB. Systemic hemodynamics affecting cardiac output during hypocapnic and hypercapnic hypoxia. J Appl Physiol. 1986;60:1230-6.

17. Dyess DL, Christenberry DP, Peeples GL. Organ blood flow redistribution in response to hypoxemia in neonatal piglets. J Invest Surg. 1998;11:381-92

18. Bauer R, Bergmann R, Walter B, Brust P, Zwiener U, Johannsen B. Regional distribution of cerebral blood volume and cerebral blood flow in newborn piglets-effect of hypoxia/hypercapnia. Develop Brain Res. 1999;112:89-98

19. Brann BS, Mayfield SR, Goldstein M, Oh W, Stonestreet BS. Cardiovascular effects of hypoxia/hypercarbia and tension pneumothorax in newborn piglets. Crit Care Med. 1994;22:1453-60.
20. Stonestreet BS, Ocampo SS, Oh W. Reductions in cardiac output in hypoxic young pigs: systemic and regional perfusion and oxygen metabolism. J Appl Physiol. 1998;85:874-82.

21. Fahey JT, Lister G. Response to low cardiac output: developmental differences in metabolism during oxygen deficit and recovery in lambs. Pediatr Res. 1989;26:180-7.

22. Hoffman GM, Stuth EA, Jaquiss RD, Vanderwal PL, Staudt SR, Troshynski TJ, et al. Changes in cerebral and somatic oxygenation during stage 1 palliation of hypoplastic left heart syndrome using continuous regional cerebral perfusion. $J$ Thorac Cardiovasc Surg. 2004; 127:223-33.

23. Tsui SSL, Schultz JM, Shen I, Ungerleider RM. Postoperative hypoxemia exacerbates potential brain injury after deep hypothermic circulatory arrest. Ann Thorac Surg. 2004;78:188-96.

\section{Authoritative}

The Journal of Thoracic and Cardiovascular Surgery is the most frequently cited thoracic/cardiovascular surgery journal in the Science Citation Index. An article in JTCVS is cited on average almost twice as often as those in the closest cardiothoracic journal. 